\title{
Studies in a newborn infant with supraventricular tachycardia and Wolff-Parkinson-White syndrome
}

\author{
H. H. Kaye, D. S. Reid, and Michael Tynan \\ From the Newcastle General Hospital, Westgate Road, Newcastle upon Tyne
}

$A$ neonatal patient with Wolff-Parkinson-White type $A$ and supraventricular tachycardia is described. Demonstration of the mechanism of the tachycardia and its termination were achieved using intracardiac electrography and cardiac pacing. Quantitative left ventricular angiography and echocardiography showed impaired left ventricular function following the arrhythmia. Serial echocardiograms demonstrated the subsequent return to normal left ventricular performance.

Intracardiac electrography has been used recently for the elucidation of the mechanism of paroxysmal supraventricular tachycardia in adult patients and older children (Goldreyer and Bigger, 197I; Wellens, 197I), but to our knowledge there has been no report of the application of this technique in the study of supraventricular tachycardia in neonates. Though it is recognized clinically that supraventricular tachycardia may lead to heart failure in infancy, there have been no reported sequential studies of left ventricular performance during the period after the arrhythmia. This report describes our findings in a baby presenting with supraventricular tachycardia in the neonatal period.

\section{Case report}

The patient was born 9 June 1973 weighing $3670 \mathrm{~g}$ at full term. Delivery was by forceps because of slow progress in the second stage of labour but his condition at birth was good. The following 6 days were uneventful but on the seventh day of life he was found to be cyanosed and breathless and had vomited 3 times during the previous night.

He was transferred to the Paediatric Cardiology Department at this hospital where on examination he was cyanosed and dyspnoeic, with a respiratory rate of Iro a minute. His pulse rate was greater than 200 a minute, peripheral pulses were barely palpable, and the liver was enlarged to $4.5 \mathrm{~cm}$ below the right costal margin in the midclavicular line. No murmurs were audible. The electrocardiogram (Fig. Ia) showed a tachycardia of 300 a minute with a normal QRS duration and a mean frontal axis of $+170^{\circ}$. Inverted $P$ waves could be seen in leads II and III, with upright $P$ waves in leads VI and V2 suggesting retrograde atrial activation. The chest $x$-ray showed an enlarged heart with normal lung fields.

Emergency cardiac catheterization was performed on the same day with a presumptive diagnosis of transposition of the great arteries, supraventricular tachycardia, and peripheral circulatory failure.

\section{Cardiac catheterization}

The data are summarized in Table $\mathrm{r}$. No structural abnormality of the heart was found but there was a leftto-right shunt at atrial level. The left atrial, right atrial, and left and right ventricular end-diastolic pressures were all raised, consistent with congestive cardiac failure. Left atrial cineangiography was performed in the right anterior oblique projection because of the possibility of a primary heart muscle disease, and from the angiogram left ventricular volumes, ejection fraction, and mean

\section{TABLE I Cardiac catheterization data}

\begin{tabular}{lll}
\hline & Pressure $(\mathrm{mmHg})$ & $\% \mathrm{O}_{2}$ satn. \\
\hline Superior vena cava & & $4 \mathrm{I}$ \\
Inferior vena cava & & 46 \\
Right atrium & I6 (mean) & $6 \mathrm{I}$ \\
Right ventricle & $44 / 16$ & 74 \\
Main pulmonary artery & $44 / 36$ & 75 \\
Pulmonary veins & & 96 \\
Left atrium & I8 (mean) & 88 \\
Left ventricle & $54 / 16$ & 87 \\
Femoral artery & $55 / 50$ & 95 \\
\end{tabular}


velocity of circumferential fibre shortening (mean VCF) were calculated. A large end-diastolic volume associated with a diminished mean VCF indicated that there was impairment of left ventricular performance (Table 2) (Tynan et al., 1974).
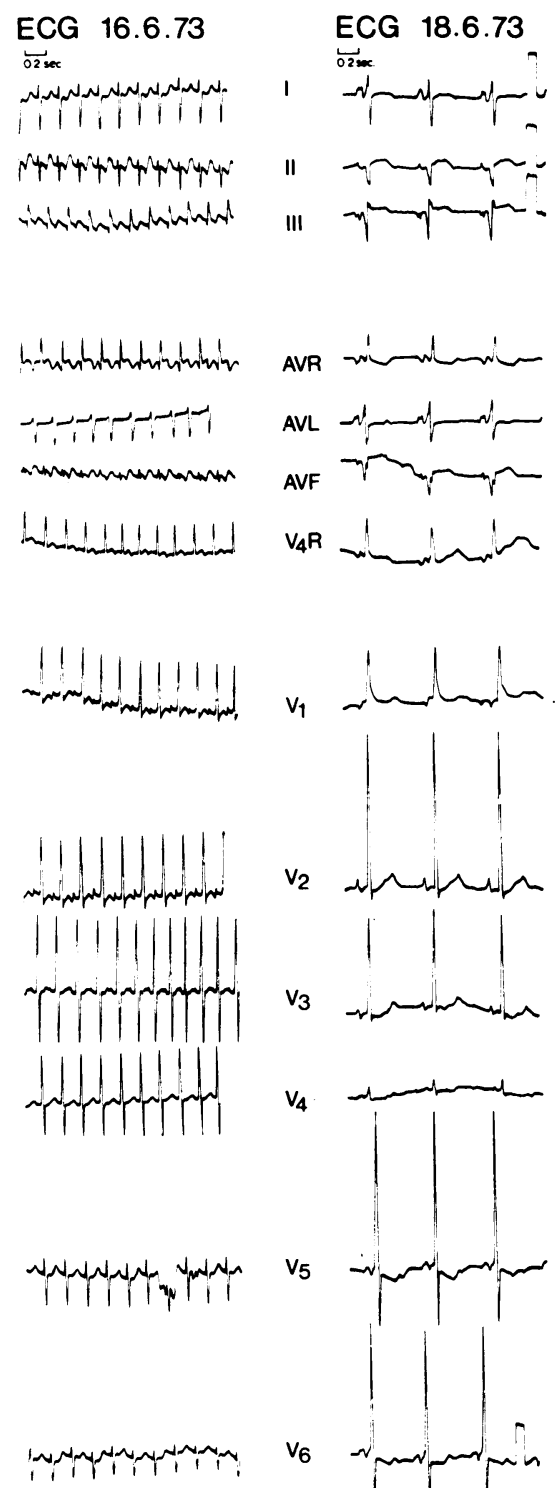

$v_{6}$

$a$

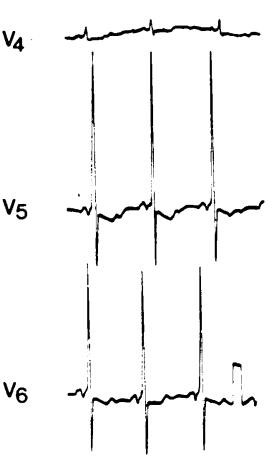

$b$

FIG. I a) Electrocardiogram on admission to unit; b) electrocardiogram after treatment showing WPW type $A$.

\section{Electrophysiology}

Before angiography a bipolar (Io $\mathrm{mm}$ ) electrode catheter $(5 \mathrm{~F})$ was introduced and positioned to lie across the tricuspid valve. The catheter was used to record the His bundle electrogram by a technique that was essentially the same as that described by Scherlag et al. (1969). The same catheter was used for pacing at rates of 60 to 100 a minute in the right atrium, in the right ventricle, and in the region of the $\mathrm{His}$ bundle.

During the tachycardia each ventricular depolarization was preceded by a His depolarization confirming the supraventricular origin of the tachycardia (Fig. 2a). Atrial activation preceded ventricular activation by 128 msec and followed the preceding ventricular activation by $100 \mathrm{msec}$. However, as no high right atrial electrogram was recorded, it was impossible to confirm that atrial activation occurred in a retrograde direction. The His bundle electrogram recorded after termination of the tachycardia (Fig. 2b) showed that the AH time was 45 msec which is shorter than the normal of 60 to II $5 \mathrm{msec}$ reported by Roberts and Olley (1972) and 50 to $105 \mathrm{msec}$ reported by Bekheit and her colleagues (1973) for infants. This suggested the presence of atrioventricular nodal bypass. The HV time in sinus rhythm was normal (Fig. 2b) but was shorter than that recorded during the tachycardia. This could have indicated the presence of an

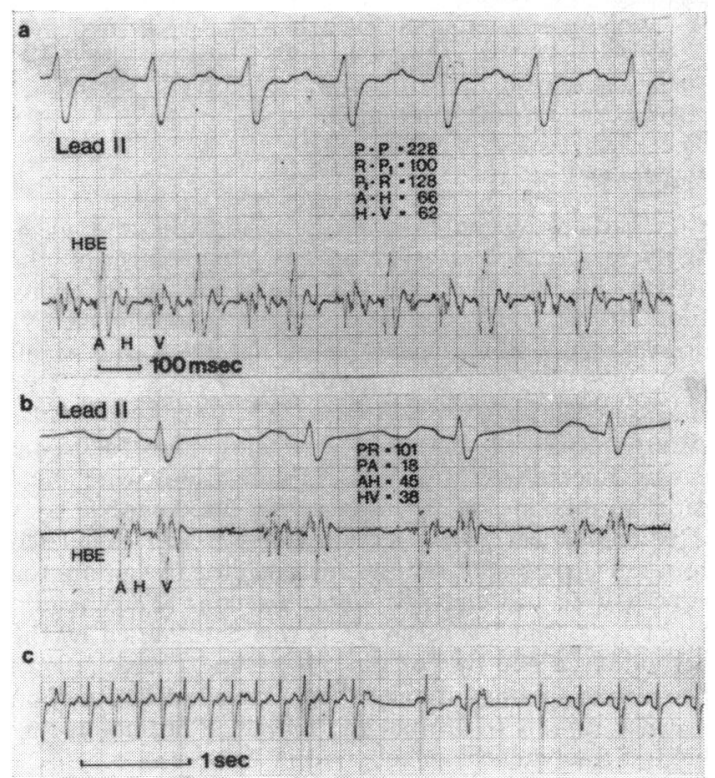

FIG. 2 a) His bundle electrogram during the supraventricular tachycardia; b) His bundle electrogram immediately following return to sinus rhythm; c) reversion to sinus rhythm during pacing. $H B E$, His bundle recording: $A$, atrial electrogram; $H, H$ is bundle electrogram; $V$, ventricular electrogram. 
TABLE 2 Left ventricular function data

\begin{tabular}{llll}
\hline & $\begin{array}{l}\text { End-diastolic } \\
\text { volume }\end{array}$ & $\begin{array}{l}\text { Ejection } \\
\text { fraction }\end{array}$ & $\begin{array}{l}\text { Mean } \\
\text { VCF }\end{array}$ \\
\hline $\begin{array}{l}\text { Cineangiography } \\
\text { 16 June 1973 }\end{array}$ & $63 \mathrm{ml} / \mathrm{m}^{2}$ & 0.66 & 0.91 \\
Echocardiography & & & \\
16 June 1973 & 0.54 & 1.03 \\
18 June 1973 & 0.65 & 1.65 \\
28 June 1973 & 0.64 & 1.45 \\
10 October 1973 & 0.78 & 2.17 \\
\hline
\end{tabular}

additional pathway causing ventricular pre-excitation, the normal HV, not shorter than normal as would be expected, being caused by rapid activation of the bundle of $\mathrm{His}$ by the atrioventricular nodal bypass (Coumel et al., 1972). The presence of delta waves on the subsequent electrocardiograms confirmed that there must be direct atrioventricular bypass or His ventricular bypass. However, it is possible that little pre-excitation was present during these recordings and the prolonged $\mathrm{HV}$ recorded during the tachycardia was the result of the rapid rate producing first degree block in the His bundle.

Pacing in the high and mid right atrium and in the ventricle did not alter the tachycardia. However, pacing in the region of the $\mathrm{His}$ bundle resulted in capture beats with incomplete compensatory pauses and termination of the tachycardia (Fig. 2c). This suggested that the mechanism of the arrhythmia was re-entry in the region of the atrioventricular junction.

\section{Progress}

After catheterization he was given digitalis and made satisfactory progress without any recurrence of the tachycardia. The electrocardiogram on the day following (Fig. Ib) and subsequently showed a shortened PR interval, with slight widening of the $Q R S$ and small delta waves in leads I, II, III, aVF, and V4 to 6, i.e. WolffParkinson-White (WPW) type A. Left ventricular performance was determined during the follow-up using echocardiography. These examinations were made using an Ekoline 20 ultrasonoscope fitted with a 2.25 $\mathrm{MHz}$ transducer. The ejection fraction was calculated from left ventricular volumes determined by cubing the end-diastolic and end-systolic dimensions (Feigenbaum et al., 1972) and the mean VCF was determined by the method described by Fortuin, Hood, and Craige (1972). The results obtained showed that left ventricular function returned rapidly to normal and remained normal during the first four months of follow-up (Table 2).

\section{Discussion}

This case demonstrates the feasibility of intracardiac electrography in the study of the mechanism of tachycardia in the neonatal patient. The His bundle electrogram was performed when no structural basis for the heart failure or peripheral circulatory failure had been demonstrated by cardiac catheterization. The electrophysiological findings suggested the presence of atrioventricular nodal bypass with either total atrioventricular bypass or His ventricular bypass. A possible explanation of these findings is the combination of atrioventricular nodal bypass by the James tract (James, I963), or by the pathway described by Lev and his colleagues (1966), and functionally active Mahaim fibres, a combination that has been described in WPW type B (Lev et al., I966). However, James (I970b) has shown that there are direct connexions between the atrial septum and ventricular septum in the neonatal period, and conduction preferentially through these connexions, with the addition of atrioventricular nodal bypass, is an alternative explanation of the findings in the neonate. It is of interest that these direct septal connexions have been demonstrated in a patient with ventricular pre-excitation (Truex, Bishop, and Downing, 1960). A further possible explanation, a left-sided lateral connexion (Kent bundle) and atrioventricular nodal bypass, seemed less likely as the response to pacing during the tachycardia suggested that the anomalous pathway was likely to be in the junctional septal region. Further definition of these pathways could have been obtained by studying the results of pacing in the right and left atria, His bundle, and right ventricle after termination of the tachycardia, but we felt that these additional procedures were not justified in this ill neonate.

The presence of a reciprocating tachycardia was suggested by the production of incomplete compensatory pauses and termination of the tachycardia by random stimulation. Since the QRS was normal during the tachycardia, the antegrade pathway was probably the normal atrioventricular nodal His pathway and the retrograde pathway one of the anomalous pathways described above. Further confirmation of this could have been obtained by studying the initiation of the tachycardia by programmed stimulation (Wellens, I97I).

Although paroxysmal tachycardia in infancy is uncommon, several series have been reported (Nadas et al., 1952; Simcha and Bonham-Carter, I971; Lundberg, 1973). The number of cases of preexcitation in these series varies: 5 of $4 \mathrm{I}$ (though an additional 4 had a short PR interval and a normal QRS suggesting atrioventricular nodal bypass) (Nadas et al., 1952), 3 of 19 (Simcha and BonhamCarter, I97I), and 23 of 47 (Lundberg, I973). It is important to identify pre-excitation in these patients for though the recurrence of tachycardia in the first year of life is the same in those with and without pre-excitation, after the first year recurrence of tachycardia is six times greater in those with 
pre-excitation (Lundberg, 1973). However, with the prophylactic use of digoxin, recurrences of tachycardia in patients with pre-excitation can be reduced (Giardina, Ehlers, and Engle, 1972). It, therefore, seems advisable to continue digoxin in this infant for at least one year.

The identification of the type of pre-excitation may also be important as it has been recently suggested that type A WPW tends to be transient and less likely to be associated with congenital heart disease than type B (Bhandhusavee, Walters, and Noonan, 1972). This transient nature of preexcitation may be caused by the postnatal maturation of the atrioventricular node and the His bundle and disappearance of the functionally active atrioventricular nodal connexions (James, 1970a).

The ventricular rate during supraventricular tachycardia tends to be higher in infancy than in older children and adults and is probably a reflection of a shorter atrioventricular nodal refractory period during infancy. However, the rate of the tachycardia in pre-excitation also depends on the functional properties of the anomalous pathways and these tend to vary from patient to patient. In a study of a small group of patients with the WolffParkinson-White syndrome, it was shown that the refractory period of the conducting tissue in children was shorter than in adults, and therefore the rate of the tachycardia tended to be higher in children (Mandel et al., 1974). However, there have been no sequential studies on the functional properties of the conducting system and anomalous pathways to determine whether they do change with age.

Cardiac failure is commonly associated with supraventricular tachycardia in infancy (Simcha and Bonham-Carter, 197I) and is often the presenting feature (Nadas et al., 1952). In this patient the presenting feature was severe cardiac failure, and impairment of left ventricular function was demonstrated angiographically, after termination of the tachycardia by the diminished mean VCF, though the ejection fraction was normal. The return to normality of left ventricular function was demonstrated by sequential echocardiography. This excluded the possibility of primary myocardial disease in this patient and therefore was of value in the subsequent management of this case.

\section{References}

Bekheit, S., Morton, P., Murtagh, J. G., and Fletcher, E. (1973). Comparison of sinoventricular conduction in children and adults using bundle of His electrograms. British Heart fournal, 35, 507.

Bhandhusavee, R. V., Walters, L. R., and Noonan, J. A. (1972). Wolff-Parkinson-White in the neonate. Nine cases including two with intra-atrial defects. American fournal of Cardiology, 29, 253.
Coumel, P., Waynberger, M., Fabiato, A., Slama, R., Aiguperse, J., and Bouvrain, Y. (1972). Wolff-ParkinsonWhite syndrome. Problems in evaluation of multiple accessory pathways and surgical therapy. Circulation, 45, 1216.

Feigenbaum, H., Popp, R. L., Wolfe, S. B., Troy, B. L., Pombo, J. F., Haine, C. L., and Dodge, H. T. (1972). Ultrasound measurements of the left ventricle. A correlative study with angiocardiography. Archives of Internal Medicine, 129, 461.

Fortuin, N. J., Hood, W. P., and Craige, E. (1972). Evaluation of left ventricular function by echocardiography. Circulation, 46, 26.

Giardina, A. C. V., Ehlers, K. H., and Engle, M. A. (1972). Wolff-Parkinson-White syndrome in infants and children. A long-term follow-up. British Heart fournal, 34, 839.

Goldreyer, B. N., and Bigger, J. T., Jr. (I97I). Site of reentry in paroxysmal supraventricular tachycardia in man. Circulation, 43, 15.

James, T. N. (1963). The connecting pathways between the sinus and the A-V node and between the right and the left atrium in the human heart. American Heart fournal, 66, 498.

James, T. N. (I970a). Cardiac conduction system: fetal and postnatal development. American fournal of Cardiology, 25, 213.

James, T. N. (1970b). Wolff-Parkinson-White syndrome: evolving concepts of its pathogenesis. Progress in Cardiovascular Diseases, 13, I59.

Lev, M., Leffler, W. B., Langendorf, R., and Pick, A. (1966). Anatomic findings in a case of ventricular pre-excitation (WPW) terminating in complete atrioventricular block. Circulation, 34, 718.

Lundberg, A. (1973). Paroxysmal tachycardia in infancy. Follow-up study of 47 subjects ranging in age from to to 26 years. Pediatrics, 5I, 26.

Mandel, W. J., Laks, M. M., Fink, B., and Obayashi, K. (1974). Comparative electrophysiologic features of the WPW. syndrome in the paediatric and adult patient. American fournal of Cardiology, 33, 155.

Nadas, A. S., Daeschner, C. W., Roth, A., and Blumenthal, S. L. (1952). Paroxysmal tachycardia in infants and children. Pediatrics, 9, 167.

Roberts, N., and Olley, P. (1972). His bundle electrogram in children. Statistical correlation of the atrioventricular conduction times in children with their age and heart rate. British Heart fournal, 34, 1099.

Scherlag, B. J., Lau, S. H., Helfant, R. H., Berkowitz, W. D., Stein, E., and Damato, A. N. (1969). Catheter technique for recording His bundle activity in man. Circulation, 39, 13.

Simcha, A., and Bonham-Carter, R. E. (197I). Paroxysmal atrial tachycardia in infants and children, Lancet, $1,832$.

Truex, R. C., Bishop, J. K., and Downing, D. F. (1960). Accessory atrioventricular muscle bundles. 2. Cardiac conduction system in a human specimen of WolffParkinson-White syndrome. Anatomical Record, 137, 417.

Tynan, M., Kaye, H. H., Reid, D. S., Ozme, S., and Hunter, A. S. (1974). Assessment of left ventricular performance in infants, children, and adults using single plane cine-angiocardiography (abstract). British Heart fournal, 36, 399.

Wellens, H. J. J. (1971). Electrical Stimulation of the Heart in the Study and Treatment of Tachycardias, p. II9. H. H. Stenfert Kroesse, N.W. Leiden.

Requests for reprints to Dr. Michael Tynan, Newcastle General Hospital, Westgate Road, Newcastle upon Tyne NE4 6BE. 